\title{
Chinese Consensus on Combination Therapy of Chronic Hepatitis B
}

\author{
Professional Staff Committee of Combination Therapy of Chronic Hepatitis B
}

I n May 2011, editorial boards of Chinese Journal of Experimental and Clinical Infectious Diseases (Electronic Edition), Chinese Journal of Liver Diseases (Electronic Edition) and Infection International (Electronic Edition) organized an expert committee to form an expert consensus on antiviral combination therapy of chronic hepatitis B (CHB). The consensus publication promoted and standardized the combination therapy concept of chronic hepatitis B. Clinical evidence of combination therapy for CHB is incomplete. The concept of combination therapy is gradually extended, from combination of antiviral drugs plus antiviral drugs, to antiviral drugs plus hepatoprotective drugs, and antiviral drugs plus immunomodulatory drugs. Therefore, editorial boards once again asked experts to analyze the new clinical evidence, and form the expert consensus on combination therapy of chronic hepatitis $\mathrm{B}$. The formulation of this consensus is according to the principles of evidence-based medicine. Large number of clinical studies of combination therapy is still in progress. This consensus can not fully answer all the problems encountered in the combination therapy of CHB. With the progress of clinical practice of antiviral therapy, and the accumulation of evidence in combination therapy, the expert committee will update the consensus timely. ${ }^{1}$

\section{ANTIVIRAL COMBINATION THERAPY OF CHRONIC HEPATITIS B}

The necessity of combination therapy of chronic hepatitis $B$

Currently, interferon $\alpha$ (IFN- $\alpha$ ) (conventional IFN $\alpha$ and PEG-IFN) and five nucleos(t)ide analogues (NUC) (such as lamivudine, adefovir dipivoxil, entecavir, telbivudine, and tenofovir dipivoxil) are approved for $\mathrm{CHB}$ treatment. Monotherapy using these drugs is the main treatment strategy. After treatment, longterm prognosis of $\mathrm{CHB}$ patients obtained significant improvement. ${ }^{1-3}$ But the response rate of monotherapy

Correspondence: Jun Cheng, No. 8 Jingshun Street East, Chaoyang District, Beijing 100015, China;

E-mail: jun.cheng.ditan@gmail.com is comparatively low (Table 1). Most of patients need long-term medication. Maintained long term response rate is also low after cessation of antiviral therapy. Prolonged usage of NUC in the treatment of CHB patients is well tolerated, but the drug resistance merged at a high rate. Monotherapy using theses drugs in the antiviral therapy of CHB patients is therefore limited. To improve the efficacy of antiviral therapy for CHB patients, combination of different antiviral drugs is an important method, including combination of NUC drugs and NUC drugs (without cross resistance) or NUC drugs and IFN- $\alpha$ (different antiviral mechanism). Combination therapy using drugs with different mechanisms may improve the efficacy of antiviral therapy. Combination therapy using NUC drugs without cross resistance may reduce drug resistance.

\section{Concept and types of antiviral combination therapy} for chronic hepatitis $B$

Antiviral combination therapy of chronic hepatitis B is the strategy of application of two or more antiviral drugs in treatment of CHB. Currently, seven drugs have been approved to treat chronic hepatitis $\mathrm{B}$, including two formulations of interferon $\alpha$ (conventional IFN- $\alpha$ and PEG-IFN) and five nucleos(t)ide analogues (lamivudine, adefovir dipivoxil, entecavir, telbivudine and tenofovir dipivoxil). Simultaneous or sequential uses of any two or more drugs are belongs to antiviral combination therapy of chronic hepatitis B. According to the start time point of clinical treatment of antiviral combination therapy, there are three types of antiviral combination therapy, such as de novo combination therapy, optimized combination therapy and rescue combination therapy (Figure 1).

Therapeutic options of antiviral combination therapy for chronic hepatitis $B$

Combination of NUC drugs and NUC drugs for CHB De novo combination therapy

At present, it is thought that de novo combination therapy is not suitable for all CHB patients. The disease progression and clinical feature should be taken into consideration. The latest evidence indicated that patients with high baseline HBV DNA levels, decompensate liver cirrhosis, or co-infection of HBV 
Table 1. Response rates (\%) to approved therapies for chronic hepatitis $B^{1,4-17}$

\begin{tabular}{|c|c|c|c|c|c|c|}
\hline \multirow{2}{*}{ Treatment response parameters } & \multicolumn{6}{|c|}{ Approved therapies } \\
\hline & LAM & ADV & ETV & LdT & TDF & PegIFN \\
\hline \multicolumn{7}{|c|}{ HBeAg-positive patients at week 48 or 52} \\
\hline Undetectable HBV DNA & $40-44$ & 21 & 67 & 60 & 76 & 25 \\
\hline HBeAg seroconversion & $16-21$ & 12 & 21 & 22 & 21 & 27 \\
\hline HBsAg loss & $<1$ & 0 & 2 & 0 & 3 & 3 \\
\hline \multicolumn{7}{|c|}{$\mathrm{HBeAg}$-positive patients during extended treatment } \\
\hline Undetectable HBV DNA & NA & $39(5.0)$ & $94(5.0)$ & $79(4.0)$ & $77(4.0)$ & $13(4.5)$ \\
\hline HBeAg seroconversion & $47(3.0)$ & $48(5.0)$ & $41(5.0)$ & $42(4.0)$ & $31(3.0)$ & $37(4.5)$ \\
\hline HBsAg loss & $0-3(2.5)$ & $2(5.0)$ & $5(2.0)$ & $1(2.0)$ & $10(4.0)$ & $8(4.5)$ \\
\hline \multicolumn{7}{|c|}{ HBeAg-negative patients at week 48 or 52} \\
\hline Undetectable HBV DNA & $60-73$ & 51 & 90 & 88 & 93 & 63 \\
\hline HBsAg loss & $<1$ & NA & $<1$ & $<1$ & 0 & 4 \\
\hline \multicolumn{7}{|c|}{ HBeAg-negative patients during extended treatment } \\
\hline Undetectable HBV DNA & $6(4.0)$ & $67(5.0)$ & NA & $84(4.0)$ & $86(3.0)$ & $18(4.0)$ \\
\hline HBsAg loss & $<1(4.0)$ & $5(5.0)$ & NA & $<1(2.0)$ & $0(4.0)$ & $8(4.0)$ \\
\hline
\end{tabular}

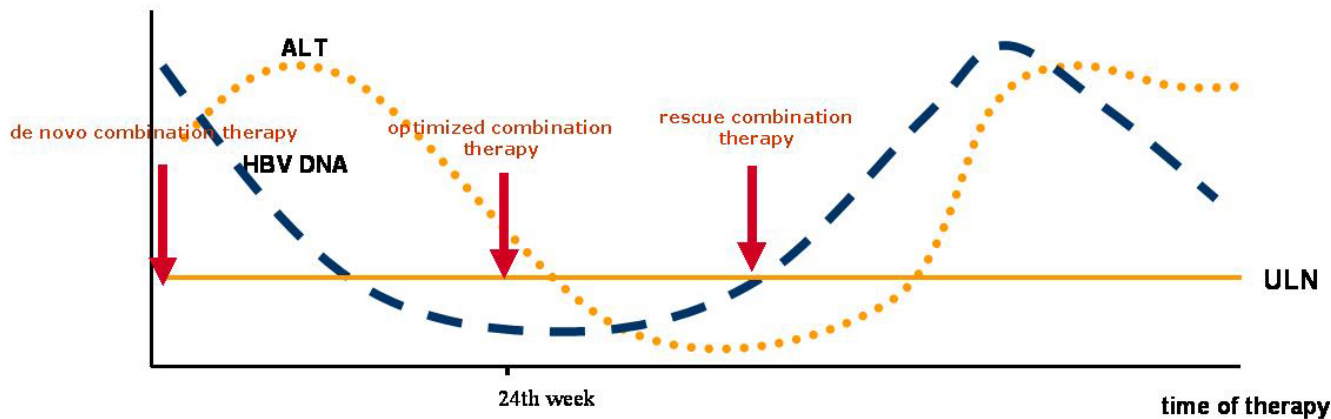

ULN: upper limits of normal

Figure 1. Types of antiviral combination therapy of chronic hepatitis $B$.

and HCV or HBV and HIV should be treated with the strategy of de novo combination therapy.

a. Indications: Patients with baseline HBV DNA $\geqslant 8 \log _{10}$ $\mathrm{IU} / \mathrm{ml}$, or with decompensate liver cirrhosis should be recommended to de novo combination therapy or NUC monotherapy, and the drug of high potency and low resistance is preferred. Studies have shown that the rate of HBV DNA under the limit of detection was low and the incidence of resistance was high in patients with higher baseline HBV DNA levels treated with LdT or LAM. ${ }^{4,5}$ De novo combination therapy could improve the efficacy and reduce resistance risk. ${ }^{6}$ Patients with higher baseline HBV DNA levels should start treatment with de novo combination therapy or with drugs of high potency and low resistance (ETV or TDF) in NUC monotherapy. Patients with decompensate liver cirrhosis usually need long-term antiviral treatment, drugs of high potency and low resistance is preferred, or de novo combination therapy using drugs of less potency or higher drug resistance in order to get efficient inhibition of $\mathrm{HBV}$ and reduce the risk of resistance. $^{7,8}$

b. Medication: The main principle of combination of different NUC drugs for CHB patients is to avoid cross resistance. In a phase II clinical study, one-year treatment of telbivudine monotherapy, lamivudine monotherapy, and the combination therapy with these two drugs for patients with hepatitis B e antigen ( $\mathrm{HBeAg}$ )-positive chronic hepatitis B showed that the combination regimens were similar to those obtained with telbivudine alone. ${ }^{9}$ It is not recommended combination of NUC drugs which have cross resistance. De novo combination therapy could start with the combinations of LAM + ADV or LdT + ADV. The study of entecavir monotherapy for 96 weeks comparing with combination therapy with ETV plus tenofovir dipivoxil (TDF) in nucleos(t)ide-naive patients with chronic hepatitis $\mathrm{B}$ showed the antiviral efficacy of ETV alone is comparable with ETV+TDF combination therapy in a mixed population $(70 \%$ HBeAg $[+])$ of nucleos(t)ide-naive $\mathrm{CHB}$ patients. The combination of ETV+TDF may provide incremental benefit in $\mathrm{HBeAg}(+)$ patients with base line $\mathrm{HBV}$ $\mathrm{DNA} \geqslant 10^{8} \mathrm{IU} / \mathrm{ml}^{10}$

Optimized combination therapy

Several studies indicated that the use of the roadmap concept could improve outcomes of chronic hepatitis B patients, including improvement of antiviral efficacy and reduction of resistance incidence in patients treated with NUC monotherapy. ${ }^{11,12}$ Combination therapy should be considered for patients who treated with NUC monotherapy and the response was suboptimal.

a. Patients treated with NUC monotherapy should be evaluated at week 12. The levels of serum HBV DNA decreased less than $2 \log _{10}$ copies/ml from baseline should be changed to combination therapy. Addiction with another NUC drugs without cross resistance or switch to more potent antiviral drugs is necessary.

b. HBV DNA level should be detected at the time point of week 24 . The responses could be divided into 
complete response, partial response and inadequate response according to the levels of serum HBV DNA at week 24 .

The patients with complete virological response (defined as undetectable HBV DNA levels) may continue treatment with the same agent, and then the frequency of follow-up can be prolonged to six months.

The extend strategies of patients with partial virological response ( $3 \log _{10}$ copies/ml $<$ HBV DNA $<$ $4 \log _{10}$ copies $/ \mathrm{ml}$ ) are variable depending on the varieties of drugs for initial treatment.

The patients receiving drugs with a low genetic barrier to resistance (e.g. lamivudine) should be considered to add another drug without cross resistance (adefovir dipivoxil or tenofovir dipivoxil) to prevent the emergence of resistance and virological breakthrough. In patients receiving a potent drug with high genetic barrier to resistance (e.g. entecavir), or a less potent drug with high genetic barrier to resistance (e.g. adefovir dipivoxil) virological monitoring is required every three months and maintains longer than 48 weeks. The optimal management of these patients with partial virological response or suboptimal virological response at week 48 should be subjected to add another NUC without cross-resistance or IFN- $\alpha$ / Peg IFN according to the treatment with the prior agent. The patients with complete virological response at week 48 the treatment may continue with the initial antiviral agent.

In patients with suboptimal virological response (HBV DNA $\geqslant 4 \log _{10}$ copies $/ \mathrm{ml}$ ), switch to or addingon a drug without cross-resistance is recommended. Virological monitoring of these patients is required every three months and maintains at least 48 weeks. The period of virological monitoring can be prolonged to six months when the HBV DNA levels are undetectable. In patients with virological breakthrough after a complete virological response, the treatment regimen based on adding a drug without cross-resistance is recommended during any stage of treatment. The period of virological monitoring is required at a 3-month interval after the treatment adaptation.

Rescue combination therapy strategy

The majority of patients need long-term therapy with NUC rather than finite treatment to maintain the

Table 2. Strategies for $\mathrm{HBV} / \mathrm{HCV}$ co-infected patients

\begin{tabular}{llll}
\hline HBV DNA & HCV RNA & ALT & Recommend \\
\hline undetectable & + & & refer to standard regimen for HCV infection \\
+ & + & $<2 \times \mathrm{ULN}$ & refer to standard regimen for HCV infection \\
+ & + & $>2 \times \mathrm{ULN}$ & PEG-IFN- $\alpha / \mathrm{IFN}-\alpha+\mathrm{RBV} \pm \mathrm{NUC}$ \\
+ & undetectable & $<2 \times \mathrm{ULN}$ & Antiviral therapy is unnecessary temporarily, and monitor HBV \\
+ & undetectable & $>2 \times \mathrm{ULN}$ & refer to regimen for HBV infection \\
& & & Antiviral therapy is unnecessary temporarily, and monitor HBV \\
\hline
\end{tabular}

Note: ${ }^{a}$ : Prevent to choose the combination therapy of IFN-alpha and LdT. sustained virological response. The risk of virological resistance will increase as the time of treatment going. Along with the variety of NUC increased, the patterns of HBV resistance also become more complicated. In case of resistance to NUC, especially for the patients with decompensate liver cirrhosis, an appropriate rescue therapy should be initiated as soon as possible. Usually virological breakthrough appears prior to biochemical breakthrough, so the initiation of rescue therapy before the biochemical breakthrough can prevent the emergence of hepatitis flare and exacerbations of liver disease. To diminish the risk of engendering multidrug resistant variant, adding on another NUC without crossresistance is preferred option. ${ }^{15,16}$

The details of rescue strategies are explained as follows:

a. Lamivudine resistance: Add adefovir dipivoxil or tenofovir dipivoxil.

b. Adefovir dipivoxil resistance: If there is rtN236T mutation, add one of lamivudine, entecavir, and telbivudine; or switch to Truvada. If there is rtA181T/ $\mathrm{V}$ mutation, add entecavir or switch to Truvada. The safety of combination with tenofovir dipivoxil and entecavir is still need to clarify.

c. Telbivudine resistance: Add adefovir dipivoxil or tenofovir dipivoxil (The safety of long-term combination therapy is still need to clarify.)

d. Entecavir resistance: Add adefovir dipivoxil or tenofovir dipivoxil (The safety of combination therapy is still need to clarify.).

e. Tenofovir dipivoxil resistance: To date, resistance to tenofovir dipivoxil has not been described. It is recommended that genotyping and phenotyping should be done in such cases by an expert laboratory to determine the cross-resistance profile. Adding one of entecavir, telbivudine, lamivudine, or entecavir is feasible (The safety of combination therapy is still need to clarify.)

\section{Combination therapy in co-infected patients with $\mathrm{CHB}$}

In Chinese population, the HBsAg carrier rate is $7.18 \%$, which is still among the high epidemic area in the world. Due to similar routes of transmission, HBV and hepatitis $\mathrm{C}$ virus (HCV), or human immunodeficiency virus (HIV) coinfection is also very common. In $\mathrm{HBV} / \mathrm{HCV}, \mathrm{HBV} / \mathrm{HIV}$ co-infected patients, different 
strategies of combination therapy should be taken according to the specific characteristics of their diseases.

\section{Treatment for $\mathrm{HBV} / \mathrm{HCV}$ co-infected patients}

Approximately 10 to $20 \%$ of $\mathrm{CHB}$ patients have coinfection with $\mathrm{HCV}$. In $\mathrm{HBV}$-infected patients, $\mathrm{HCV}$ co-infection accelerates liver disease progression and increases the incidence of liver cirrhosis, decompensate liver disease, and HCC. For most of the patients, the replication of HBV was suppressed by $\mathrm{HCV}$ due to interaction between the two viruses. The strategies of these co-infected patients should be formulated according to the levels of HBV DNA, HCV RNA, and serum ALT levels (Table 2). There is a potential risk of $\mathrm{HBV}$ reactivation and liver disease progression after clearance of HCV that may release the suppression of $\mathrm{HBV}$ replication. Therefore, the monitoring of $\mathrm{HBV}$ DNA levels and relevant virological parameters is necessary during the treatment for HCV infection. ${ }^{17}$

\section{Treatment for HBV/HIV co-infected patients}

Approximately $6 \%$ to $13 \%$ of CHB patients have coinfection with HIV. In HBV-infected patients, HIV coinfection may increase HBV DNA levels and reduce the incidence of spontaneous HBeAg seroconversion, which may exacerbate liver disease and increase the liver disease-related mortality. In HBV/HIV co-infected patients, the selection of antiviral therapy regimens for HBV infection depends on the strategies of highly active antiretroviral therapy (HAART) for HIV infection. If the co-infected patients need to be treated simultaneously for both HIV and HBV, NUC for HBV antiviral therapy should be selected in the strategies of HAART such as the strategy which includes both tenofovir dipivoxil and lamivudine, or Truvada. In the patients receiving the strategy of HAART that includes lamivudine only for HBV infection, the risk of virological resistance should be monitored closely and the strategy should be changed if necessary. Lamivudine, tenofovir dipivoxil, or entecavir monotherapy may increase the risk of HIV resistance, so the strategy for patients with HBV infection should not include above-mentioned drugs, instead of which adefovir dipivoxil, telbivudine, or IFN- $\alpha$ can be selected if the patients don't need the HAART for HIV infection temporarily. ${ }^{18}$

\section{A N T I - I N F L A M M A T O R Y A N D HEPATOPROTECTIVE DRUGS IN COMBINED TREATMENT OF CHRONIC HEPATITIS B}

The application of anti-inflammatory and hepatoprotective drugs in treatment of chronic hepatitis $B$ had a long history. The anti-inflammatory and hepatoprotective drugs had played an important role in treatment of CHB until antiviral drugs were developed. At present, anti-inflammatory and hepatoprotective drugs mainly include glycyrrhizic acids, milk thistles, schisandra formulation and its derivatives, bicyclol (a monomeric compound produced by chemical synthesis), cell membrane protective agent, and antioxidant, etc. In recent years, more and more evidence reveals that the combination of antivirus drugs and anti-inflammatory and hepatoprotective drugs may be one of better treatment options of CHB.

\section{Bicyclol in combined treatment of CHB}

The efficacy and safety profiles of adefovir dipivoxil plus bicycle combination therapy regimen have been explored. This multi-centered, randomized, controlled clinical trial is to compare the efficacy of bicyclol tablet combined with adefovir dipivoxil and adefovir dipivoxil alone in treatment of $\mathrm{CHB} .{ }^{19}$ A total of 250 patients with $\mathrm{CHB}$ were randomly assigned to receive oral adefovir dipivoxil $10 \mathrm{mg}$, once daily, and oral bicyclol tablet $25 \mathrm{mg}$, tid (combination group, $\mathrm{n}=$ 125 ) or oral adefovir dipivoxil $10 \mathrm{mg}$ alone, once daily (control group, $n=125$ ). Both groups were treated for 48 weeks. AT week 48, HBV DNA detectable rate, HBeAg loss or seroconversion rate in combination group and control group were $34.4 \%$ and $31.7 \%$, 29.5\% versus $25.8 \%$, and $20.5 \%$ versus $18.3 \%$, respectively, without significant difference $(P>0.05)$. Serum ALT and AST in both groups significantly decreased, with reduction of $123.1 \pm 25.6 \mathrm{U} / \mathrm{L}$ versus $100.1 \pm 30.6$ $\mathrm{U} / \mathrm{L}$, and $95.5 \pm 23.6 \mathrm{U} / \mathrm{L}$ versus $85.0 \pm 27.5 \mathrm{U} / \mathrm{L}$, respectively (combination group versus control group) $(P<0.01)$. Normalization rate of serum ALT and AST in combination group were $78.7 \%$ and $68.7 \%$, compared with $60 \%$ and $54.2 \%(P<0.01)$. At the end of treatment, inflammatory necrosis score in both groups has been decreased. Moreover the reduction of Knodell score in combination group is significantly higher that that in control group $(3.8 \pm 2.9$ and $2.4 \pm$ 2.3 , respectively) $(P<0.05)$. No drugs-related adverse events occurred in both groups. Thus, efficacy of adefovir dipivoxil combined with bicyclol in treatment of $\mathrm{CHB}$ was superior to adefovir dipivoxil alone, with improvement in liver function and histology. In addition, combination therapy had not negative influence on antiviral effect, but favorable safety.

Based on the above study, experts suggested that bicyclol combined with adefovir dipivoxil could inhibit HBV replication, and improve liver function and liver histology score. However, indication, course, evaluation index of efficacy, and long term outcome of combination of these two drugs need to be further determined.

\section{Other hepatoprotective drugs in combined treatment of chronic hepatitis $B$}

Chinese experts had assessed efficacy of glycyrrhizic acids in treatment of CHB by meta analysis. Results showed that glycyrrhizic acids could improve 
symptoms and signs in patients with $\mathrm{CHB}$, and facilitate recovery of their liver function. But due to low evidence level of evidence-based medicine included by methodology in trials of meta analysis, the above results need further validation by randomized controlled trials with rigorous design and methodology of high quality. ${ }^{20,21}$

Results of several single center, small randomized, controlled trials comparing efficacy of milk thistles combined with interferon $\alpha$ in treatment of hepatitis B, which were published currently, showed that recovery of liver function in combination group was better than that of interferon $\alpha$ alone group. ${ }^{22,23}$

Since no publication of related article was retrieved, the value of other hepatoprotective drugs in treatment of CHB need further research through well designed clinical trials.

\section{IMMUNOMODULATOR DRUGS IN COMBINATION THERAPY OF CHB}

Immune system plays a vital role in control of HBV infection. Yet antiviral agents available today are not potential enough to rebuild effective anti-HBV immune. So physicians hope combination therapy of immunomodulators (ie. IFN- $\alpha$, thymosin $\alpha-1$, Thymopentin, interleukins, etc) may enhance the antiviral effect of other anti-HBV agents.

\section{IFN- $\alpha$ in the combination therapy of CHB}

Meta analysis showed the rates of HBV DNA negativity, $\mathrm{HBeAg}$ loss and $\mathrm{HBsAg}$ loss are $37 \%$, $33 \%$ and $7.8 \%$ for $\mathrm{HBeAg}$ positive patients who took conventional IFN- $\alpha .{ }^{24}$ So the response rate of monotherapy of conventional IFN- $\alpha$ is still not satisfactory. The HBeAg loss rate is only $32 \%$ for HBeAg positive CHB patients (87\% Asians) using Peg-IFN $\alpha$-2a monotherapy, according to the results of international, multi-centered, randomized and controlled clinical trial of PegIFN- $\alpha-2 a$, treated for 48 weeks and followed for 24 weeks. ${ }^{25,26}$

Several clinical trials of IFN- $\alpha$ plus NUC therapy showed that combination therapy may bring higher rate of HBV DNA negativity and $\mathrm{HBeAg}$ seroconversion and lower rate of NUC resistance comparing with NUC monotherapy. ${ }^{27-29}$ Yet these studies are not welldesigned RCT studies. Further studies are needed to verify this conclusion.

\section{Indications for combination therapy of IFN- $\alpha$ and NUC}

CHB patients with unsatisfactory response to IFN- $\alpha$ may be considered for NUC add-on therapy. Baseline $\mathrm{HBeAg}, \mathrm{HBsAg}$ and HBV DNA levels and dynamics of these indices during IFN- $\alpha$ therapy may predict the sustained response to IFN- $\alpha .{ }^{30-32}$ Patients treated with IFN- $\alpha$ may be considered for combination of NUC at week 24 according to the dynamics of $\mathrm{HBeAg}$, HBsAg and HBV DNA levels. ${ }^{33}$

a. $\mathrm{HBeAg}$ positive patients who have taken 24 weeks IFN- $\alpha$ therapy with HBV DNA $\geqslant 5 \log _{10}$ copies $/ \mathrm{ml}$, $\mathrm{HBeAg} \geqslant 100 \mathrm{PEI} \mathrm{U} / \mathrm{ml}$ or HBsAg $\geqslant 20000 \mathrm{IU} / \mathrm{ml}$ should be considered for combination therapy with NUC.

b. $\mathrm{HBeAg}$ negative patient who have taken 24 weeks IFN- $\alpha$ therapy with HBV DNA $\geqslant 5 \log _{10}$ copies $/ \mathrm{ml}$, and HBsAg decrease $\leqslant 1 \log _{10} \mathrm{IU} / \mathrm{ml}$ should be considered for combination therapy with NUC.

Re-evaluation of HBV DNA, HBeAg, HBsAg is recommended after 24 weeks combination therapy to decide future treatment.

Patients with unsatisfactory response to NUCs may also be considered for combination therapy with IFN- $\alpha$. Compared with NUC monotherapy, combination therapy with IFN- $\alpha$ may enhance antiviral efficacy and decrease resistance. Also re-evaluation of HBV DNA, HBeAg, HBsAg is recommended after 24 weeks combination therapy to decide future treatment regimens. Patients who have HBV DNA negativity and $\mathrm{HBeAg}$ seroconversion or HBsAg loss may take IFN- $\alpha$ till week 72 . And patients who have HBV DNA negativity and insignificant decrease of $\mathrm{HBeAg}$ and/or HBsAg may stop IFN- $\alpha$ and take NUC for infinite term of therapy.

\section{Regiments for combination therapy of IFN- $\alpha$ and NUC}

Combination therapy of IFN- $\alpha$ and lamivudine

Previous studies showed combination therapy of IFN- $\alpha$ and NUCs may enhance the antiviral efficacy, when compared with IFN- $\alpha$ or NUCs monotherapy. PegIFN$\alpha-2 b$ treated patients who took lamivudine at week 4 and continued combination therapy for 52 weeks may have higher rate of $\mathrm{HBeAg}$ seroconversion at the end of 24 weeks follow-up. ${ }^{28}$ Another study showed HBeAg negative CHB patients who took LAM and PegIFN- $\alpha-2 b$ have preferable biochemical response and HBV resistance profile when compared with LAM monotherapy (biochemical response: $72.2 \%$ vs. $25 \%$, virological breakthrough: 0 vs. $25 \%) \cdot{ }^{34} \mathrm{HBeAg}$ positive patients who took PegIFN- $\alpha-2 \mathrm{a}$ and LAM combination therapy have $8 \%$ HBsAg seroconversion at week 48 and $30 \%$ at week $96 .{ }^{35}$ Eight-hundred and fourteen $\mathrm{HBeAg}$ positive $\mathrm{CHB}$ patients were randomized to PegIFN- $\alpha-2 a+$ placebo, PegIFN- $\alpha-2 a+$ LAM, LAM monotherapy for 48 weeks and were followed for 24 weeks. At the end of follow-up, PegIFN- $\alpha-2 \mathrm{a}+$ placebo group and PegIFN- $\alpha-2 a+$ LAM groups have preferable HBeAg seroconversion rates when compared with LAM monotherapy group (32\%, $27 \%$ vs. $19 \%)$. And PegIFN- $\alpha-2 a+$ placebo group and PegIFN- $\alpha-2 a+$ LAM groups have more patients with HBV DNA $\leqslant 10^{4}$ copies/ml when compared with LAM monotherapy group $(32 \%, 34 \%$ vs $22 \%)$. Patients took PegIFN- $\alpha$ 2a therapy (PegIFN- $\alpha-2 a+$ placebo or LAM) have 6 
patients achieved HBsAg seroconversion, while no patients in LAM monotherapy group achieved HBsAg seroconversion. $^{26}$

\section{Combination therapy of IFN- $\alpha$ and adefovir dipivoxil}

Comparing with IFN- $\alpha-2 b$ monotherapy, the study showed that combination of IFN $\alpha-2 b$ and adefovir dipivoxil for 48 weeks may achieve preferable profile of HBV DNA negativity, $\mathrm{HBeAg}$ seroconversion and HBsAg seroconversion ( $86 \%$ vs $50 \%, 50 \%$ vs. $36 \%$, $14 \%$ vs. $0 \%$, respectively). ${ }^{36}$ Combination therapy of PegIFN- $\alpha-2 b$ and ADV for CHB patients may bring lower HBV DNA and HBsAg levels. When compared baseline, patents with combination therapy have significantly lower intrahepatic ccc DNA level. ${ }^{37}$ One hundred and twenty $\mathrm{HBeAg}$ positive Chinese $\mathrm{CHB}$ patients were randomized to PegIFN- $\alpha-2 a$, PegIFN- $\alpha-$ $2 \mathrm{a}+\mathrm{ADV}, \mathrm{ADV}$ for 48 weeks. At the end of treatment, PegIFN- $\alpha-2 \mathrm{a}$ alone group and PegIFN- $\alpha-2 \mathrm{a}+\mathrm{ADV}$ group have preferable HBeAg loss when compared with ADV alone group (44.7\%, 54.3\% vs. 22.5\%). And PegIFN- $\alpha-2 \mathrm{a}$ alone group and PegIFN- $\alpha-2 \mathrm{a}+$ ADV groups have more patients achieved $\mathrm{HBe} A g$ seroconversion when compared with ADV group ( $44.7 \%$, $51.4 \%$ vs. $17.5 \%) .{ }^{38}$ Seventeen percent patients taken combination therapy of PegIFN- $\alpha-2 \mathrm{a}$ and ADV for 48 weeks have HBsAg loss at the end of treatment. While patient were followed till 96 weeks, $22 \%$ patients lose HBsAg. ${ }^{39}$ Four percent $\mathrm{HBeAg}$ positive patients who took combination therapy of PegIFN- $\alpha-2 \mathrm{a}$ and ADV at the end of 48 weeks treatment and $24 \%$ at the end of 96 weeks treatment, significantly higher than that of monotherapy. ${ }^{35}$

\section{Combination therapy of IFN- $\alpha$ and telbivudine}

Studies showed combination therapy of PegIFN and LdT may increase risk of peripheral neuropathy. ${ }^{40-42}$ Combination of PegIFN and LdT should be prohibited. Combination therapy of IFN- $\alpha$ and entecavir

Till now, no RCT studies about combination therapy of IFN- $\alpha$ and entecavir for CHB have been reported. Considering the preferable profile of lamivudine/ adefovir dipivoxil and IFN- $\alpha$ combination therapy, it is suggested the careful combination of entecavir and IFN- $\alpha$ may be considered for $\mathrm{CHB}$ patients in further study. Yet further large sample, multi-centered RCT studies are urged to verify this regimen.

\section{To-1 in combination therapy of CHB}

Immunomodulator besides IFN- $\alpha$ agent have also been used for combination therapy for CHB. Yet studies mainly focused on $\mathrm{T} \alpha-1$ and less are reported about other immunomodulators.

In CHB patients, T $\alpha-1$ may enhance Th1 response, inhibit Th2 cytokines production and rebuild the balance of Th1/Th2, thus to help the clearance of HBV. ${ }^{43}$ When T $\alpha-1$ is used in combination with IFN- $\alpha$, it may promote the production of Th1 cytokines, and inhibit the Th2 cytokines induced by IFN- $\alpha{ }^{44}$ So T $\alpha-1$ complements the effect of anti-HBV agents. And T $\alpha-1$ has nice safety profile in decade's clinical practice.

Lim et al. reported a double-blind, randomized, placebo-controlled study to compare IFN- $\alpha$ monotherapy with combination of IFN- $\alpha$ and T $\alpha-1$ in treatment of CHB patients. Results indicated that combination group has higher rate of HBeAg loss when compared with monotherapy group. ${ }^{45}$ Mao et al. reported a meta analysis of combination therapy of IFN- $\alpha$ and T $\alpha-1$ for HBeAg positive CHB patients. In this meta analysis, total 535 cases from 7 RCT studies were enrolled. And study showed that combination therapy have preferable HBV DNA negativity, ALT normalization, $\mathrm{HBeAg}$ loss and $\mathrm{HBeAg}$ seroconversion at end of treatment and follow-up, when compared with IFN- $\alpha$ monotherapy. Combination therapy shows no extra adverse events when compared with IFN- $\alpha$ monotherapy. ${ }^{46}$

Combination therapies of T $\alpha-1$ and NUC mainly focus on lamivudine and adefovir dipivoxil. Zhang et al reported a meta-analysis compared between combination therapy of LAM + T $\alpha-1$ and LAM monotherapy in $\mathrm{HBeAg}$ positive $\mathrm{CHB}$ patients. In this meta analysis, total of 583 cases from 8 RCT studies were enrolled. And study showed that combination therapy have preferable HBV DNA response, ALT normalization and $\mathrm{HBeAg}$ seroconversion when compared with lamivudine monotherapy. ${ }^{47}$

T $\alpha-1$ complements the effect of anti-HBV agents. And available studies showed $\mathrm{T} \alpha-1$ may enhance the efficacy of anti-HBV agents and has nice safety profile in decade's clinical practice. Yet large-sale, multicentered, randomized and controlled studies are needed to verify $\mathrm{T} \alpha-1$ use in combination therapy of $\mathrm{CHB}$. As for other immunomodulators, no suggestions can be made for the deficiency of evidence and further studies are urged.

\section{Committee Members of Combination Therapy of Chronic Hepatitis B}

Yong-ping Chen, Jun Cheng, Ming-liang Cheng, Lei Dong, Xiao-guang Dou, Tao Han, Jun Li, Ke Li, Xu Li, Zhi-wei Li, Qing-hua Meng, Wang-hua Ren, Deming Tan, Hong Tang, Mao-rong Wang, Hao Wang, Lei Wang, Qing Xie, Wen Xie, Yao Xie, Hui-chun Xing, Yan-yan Yu, Hong-fei Zhang, Quan Zhang, Zhen Zhen, Xia-qiu Zhou.

\section{REFERENCES}

1. Niederau C, Heintges T, Lange S, Goldmann G, Niederau CM, Mohr L, et al. Long-term follow-up of HBeAg-positive patients treated with interferon alfa for chronic hepatitis B. N Engl J Med 1996;334:1422-1427.

2. Liaw YF, Sung JJ, Chow WC, Farrell G, Lee CZ, Yuen H, et al. Lamivudine for patients with chronic hepatitis $\mathrm{B}$ and advanced liver disease. N Engl J Med 2004;351:1521-1531.

3. Di MV, Marzano A, Lampertico P, Andreone P. Santantonio T. Almasio PL, et al. Clinical outcome of HBeAg-negative chronic hepatitis $\mathrm{B}$ in relation to virological response to lamivudine. 
Hepatology 2004;40: 883-891.

4. Wang L, Yan J, Zhang Z, Wang J, Du Y, Li X, et al. Occurrence and predictive factors of hepatitis $\mathrm{B}$ virus polymerase YMDD variation among patients with chronic hepatitis B and liver cirrhosis during lamivudine therapy. C J Hepotol 2004;12:14-17.

5. Zoulim F, Perrillo R. Hepatitis B: reflections on the current approach to antiviral therapy. J Hepatol 2008;48 (Suppl 1):s2-s19.

6. Lampertico P, Vigano M, Manenti E, Iavarone M, Sablon E, Colombo M. Low resistance to adefovir combined with lamivudine: a 3-year study of 145 lamivudine-resistant hepatitis B patients. Gastroenterology 2007;133:1445-1451.

7. Yang YD, Zheng L, Jie HY. De novo lamivudine and adefovir dipivoxil combination therapy for patients with decompensated cirrhosis resulting from chronic hepatitis B. Hepatol Int 2010;4:134

8. Wan M. The present situation and pondering on antiviral therapy in patients with decompensated cirrhosis. C J Hepotol 2010;18:483-485.

9. Lai CL, Leung N, Teo EK, Tong M, Wong F, Hann HW, et al. A 1-year trial of telbivudine, lamivudine, and the combination in patients with hepatitis B e antigen-positive chronic hepatitis B. Gastroenterology 2005; 129:528-536.

10. Lok AS, Trinh H, Carosi G, Akarca U, Gadano A, Habersetzer F, et al. Entecavir (ETV) monotherapy for 96 weeks is comparable to combination therapy with ETV plus tenofovir (TDF) in nucleos(t)idenaive patients with chronic hepatitis B (CHB): the BE-LOW study. 2011. AASLD.

11. Keeffe EB, Zeuzem S, Koff RS, Dieterich DT, Esteban-Mur R, Gane EJ, et al. Report of an international workshop: roadmap for management of patients receiving oral therapy for chronic hepatitis B. Clin Gastroenterol Hepatol 2007;5:890-897.

12. Chinese Roadmap Expert Group for Telbivudine Treatment. Chinese roadmap for treating chronic hepatitis B with telbivudine. C J Hepotol 2008; $16: 323-325$

13. Liaw YF. On-treatment outcome prediction and adjustment during chronic hepatitis B therapy: now and future. Antivir Ther 2009;14(1):13-22.

14. Lai CL, Gane E, Liaw YF, Hsu CW, Thongsawat S, Wang Y, et al. Telbivudine versus lamivudine in patients with chronic hepatitis B. N Engl J Med 2007;357:2576-2588.

15. Lok AS, McMahon BJ. Chronic hepatitis B: update 2009. Hepatology 2009;50:661-662.

16. European Association For The Study Of The Live. EASL Clinical Practice Guidelines: management of chronic hepatitis B. J Hepatol 2009;50:227-242.

17. Committee of experts on antiviral therapy of chronic hepatitis C. Experts consensus on antiviral therapy of chronic hepatitis C. C J Exp Clin Infect Dis (Electro Edi) 2009;3:343-352.

18. Sherman M. Strategies for managing coinfection with hepatitis B virus and HIV. Cleve Clin J Med 2009;76(Suppl 3):S30-S33.

19. Xie W, Shi G, Zhang H, Zhao G, Yu Z, Lang Z, et al. A randomized, multi-central, controlled study of patients with hepatitis $B$ e antigenpositive chronic hepatitis B treated by adefovir dipivoxil or adefovir dipivoxil plus bicyclol. Hepatol Int 2012;6:441-448.

20. Qin G, Shi G, Song Y, Chen M. Meta-analysis of document on diammonium Glycyrrhizinate in treatment of patients with chronic hepatitis B. C J Infect Dis 2005;23:333-337.

21. Xia Y, Liu J. Glycyrrhizin and derivatives for treatment of chronic hepatitis B:A systematic review of randomized controlled trials. C J Integr Tradit West Med Liver Dis 2007;17:304-309.

22. Bao F, Xie J. Combination therapy of milk thistles and interferon on hepatitis B. J Qiqihar Univer Med 2006;27:1185-1186.

23. Gou W, Wang Y. Combination therapy of milk thistles and interferon $\alpha-2 b$ on hepatitis B. J Clin Hepatol 2004;20:302.

24. Wong DK, Cheung AM, O' Rourke K, Naylor CD, Detsky AS, Heathcote J. Effect of alpha-interferon treatment in patients with hepatitis B e antigen-positive chronic hepatitis B. A meta-analysis. Ann Intern Med 1993;119:312-323.

25. Harris JM, Martin NE, Modi M. Pegylation: a novel process for modifying pharmacokinetics. Clin Pharmacokinet 2001;40:539-551.

26. Lau GK, Piratvisuth T, Luo KX, Marcellin P, Thongsawat S, Cooksley G, et al. Peginterferon Alfa-2a, lamivudine, and the combination for HBeAg-positive chronic hepatitis B. N Engl J Med 2005;352:2682-2695.

27. Sarin SK, Sood A, Kumar M, Arora A, Amrapurkar D, Sharma BC, et al. Effect of lowering HBV DNA levels by initial antiviral therapy before adding immunomodulator on treatment of chronic hepatitis B. Am J Gastroenterol 2007;102:96-104.
28. Chan HL, Leung NW, Hui AY, Wong VW, Liew CT, Chim AM, et al. A randomized, controlled trial of combination therapy for chronic hepatitis B: comparing pegylated interferon-alpha $2 \mathrm{~b}$ and lamivudine with lamivudine alone. Ann Intern Med 2005;142:240-250.

29. Wong VW, Wong GL, Yan KK, Chim AM, Chan HY, Tse CH, et al. Durability of peginterferon alfa- $2 \mathrm{~b}$ treatment at 5 years in patients with hepatitis B e antigen-positive chronic hepatitis B. Hepatology 2010;51:1945-1953.

30. Fried MW, Piratvisuth T, Lau GK, Marcellin P, Chow WC, Cooksley $\mathrm{G}$, et al. $\mathrm{HBeAg}$ and hepatitis B virus DNA as outcome predictors during therapy with peginterferon alfa-2a for $\mathrm{HBeAg}$-positive chronic hepatitis B. Hepatology 2008;47:428-434.

31. Moucari R, Mackiewicz V, Lada O, Ripault MP, Castelnau C, Martinot-Peignoux M, et al. Early serum HBsAg drop: a strong predictor of sustained virological response to pegylated interferon alfa2a in HBeAg-negative patients. Hepatology 2009;49:1151-1157.

32. Brunetto MR, Moriconi F, Bonino F, Lau GK, Farci P, Yurdaydin C, et al. Hepatitis B virus surface antigen levels: a guide to sustained response to peginterferon alfa-2a in $\mathrm{HBeAg-negative} \mathrm{chronic} \mathrm{hepatitis}$ B. Hepatology 2009;49:1141-1150.

33. Wan M, Wong X. Suggestion on chronic hepatitis B with interferon (2010). C J Infect Dis 2010;28:193-200.

34. Vassiliadis T, Tziomalos K, Patsiaoura K, Zagris T, Giouleme O, Soufleris $\mathrm{K}$, et al.Lamivudine/pegylated interferon alfa-2b sequential combination therapy compared with lamivudine monotherapy in HBeAg-negative chronic hepatitis B. J Gastroenterol Hepatol 2007;22:1582-1588.

35. Cao Z, Zhang Y, Ma L, Sun G, He Z, Liu Y, et al. Treatment of $\mathrm{HBeAg-positive} \mathrm{CHB}$ infection with peginterferon alfa-2a [40KD] puls lamivudine or adefovir for 96 weeks resulting in high rate of HBsAg clearance seroconversion rates. 2010. AASLD.

36. Zafar S, Haque IU, Rehman AU,, et al. Comparison of adefovir and standard interferon combination with standard interferon or adefovir for treatment of chronic hepatitis B. Pakistan J Gastroenterol 2009;23:9-15.

37. Wursthorn K, Lutgehetmann M, Dandri M, Volz T, Buggisch P, Zollner $\mathrm{B}$, et al. Peginterferon alpha-2b plus adefovir induce strong cccDNA decline and HBsAg reduction in patients with chronic hepatitis B. Hepatology 2006;44:675-684.

38. Ma W, Zhou B, Ao F, Zhou D, Hu Y, He Q, et al. Higher sustained post-treatment virologic response following peginterferon alfa- $2 \mathrm{a} \pm$ adefovir compared with adefovir monotherapy in $\mathrm{HBeAg}$-positive patients. 2009. AASLD.

39. Takkenberg B, Zaaijer H, Weegink C, Terpstra V, Dijkgraaf M, Jansen1 P, et al. Baseline HBsAg level predict HBsAg loss in CHB patients treated with a combination of peginterferon alfa- $2 \mathrm{a}$ and adefovir: an interim analysis. 2009. EASL.

40. Canada H. Risk of peripheral neuropathy in patients treated with telbivudine (SEBIVO) and interferon- For Health Professionals. (Accessed at http://www.hc-sc.gc.ca/dhp-mps/medeff/advisories-avis/ prof/_2008/sebivo_hpc-cps-eng.php).

41. European Medicines Agency. Risk of peripheral neuropathy with Sebivo (telbivudine). Media Release 2008;2:14.

42. Liu M, Yi W, Cai H. Myositis and peripheral neuropathy associated with telbivudine and interferon. Adver Drug React J 2010;12:130-131.

43. Baumann CA, Badamchian M, Goldstein AL. Thymosin alpha 1 antagonizes dexamethasone and CD3-induced apoptosis of $\mathrm{CD} 4^{+} \mathrm{CD} 8^{+}$thymocytes through the activation of cAMP and protein kinase $\mathrm{C}$ dependent second messenger pathways. Mech Ageing Dev 1997;94:85-101.

44. Loggi E, Gramenzi A, Margotti M, Cursaro C, Galli S, Vitale G, et al. In vitro effect of thymosin-alpha1 and interferon-alpha on Th1 and Th2 cytokine synthesis in patients with eAg-negative chronic hepatitis B. J Viral Hepat 2008;15:442-448.

45. Lim SG, Wai CT, Lee YM, Dan YY, Sutedja DS, Wee A, et al. A randomized, placebo-controlled trial of thymosin-alpha1 and lymphoblastoid interferon for $\mathrm{HBeAg}$-positive chronic hepatitis B. Antivir Ther 2006;11:245-253.

46. Mao H, Shi T. Treatment with interferon and thymosin alpha-1 versus interferon monotherapy for $\mathrm{HBeAg}$ positive chronic hepatitis B: a Meta-analysis. C J Hepatol 2011;19:29-33.

47. Zhang Y, Chen E, Yang J, Duan Y, Tang H. Treatment with lamivudine versus lamivudine and thymosin alpha-1 for e antigen-positive chronic hepatitis B patients: a meta-analysis. Virol J 2009;6:63. 